\title{
Representações da Violência por Professores
}

\author{
Maria das Graças de Carvalho ${ }^{1}$; Gislene Farias de Oliveira ${ }^{2}$; Ana Cárita ${ }^{3}$
}

Resumo: A violência no espaço escolar tem sido motivo de preocupação em todo o mundo. O objetivo foi analisar a violência no espaço escolar, à partir da percepção dos professores no município de Simões-PI. Fizeram parte da amostra, 49 docentes, sendo 77,6\% mulheres e 22,4\% homens. Desses, 98,0\% observaram episódios de violência na escola, sendo o tipo mais comum, a patrimonial $28,5 \%$, seguida da física $27,2 \%$; da negligência $22,8 \%$ e da psicológica em $21,0 \%$ dos casos. Dentre as modalidades mais citadas estiveram presentes nas respostas, a Intimidação (40,8\%); a Difamação (16,3\%); o Assédio moral (12,2\%); a Injúria (4,1\%) e, outras $(26,5 \%)$. Com relação ao local onde foram observadas as violências, Foram citados: Dentro da Escola 40 $(81,6 \%)$; Na rua $3(6,1 \%)$; Outro lugar $2(4,1 \%)$; Não responderam a esta questão $4(8,2 \%)$. Quanto às Representações sociais de Violência, sobressaiu-se uma única categoria: Ação maléfica. $O$ estudo concluiu que a violência no ambiente escolar ainda necessita ser mais discutida, para que se possa conhecer aspectos associados às diversas variáveis implicadas, não demonstradas no presente estudo. Nesse sentido evidencia-se a importância que se deva dar para a identificação dos possíveis casos de problemas acadêmicos, visando prevenir-se a tempo, as situações de risco.

Palavras-Chave: Violência, Espaço-escolar, Representações sociais

\section{Violence Representations by Teachers}

\begin{abstract}
The violence at school has been of concern worldwide. The aim was to analyze violence at school, to from the perception of teachers in the municipality of Simões-IP. Composed the sample, 49 teachers, with $77.6 \%$ women and $22.4 \%$ men. Of these, $98.0 \%$ observed episodes of school violence, the most common type, the equity $28.5 \%$, then $27.2 \%$ of physics; $22.8 \%$ of neglect and psychological in $21.0 \%$ of cases. Among the most cited forms were present in the responses, the intimidation (40.8\%); Defamation (16.3\%); the moral harassment $(12.2 \%)$; to injury $(4.1 \%)$ and others $(26.5 \%)$. In relation to where the violence were observed, they were cited: Inside the School $40(81.6 \%)$; On the street $3(6.1 \%)$; Another place $2(4.1 \%)$; They did not answer this question $4(8.2 \%)$. As for Social representations of violence, stood out a single category: evil action. The study found that violence in the school environment needs to be further discussed, so that we can meet the various aspects associated variables involved, not demonstrated in this study. In this sense evidences the importance that we should give to identify possible cases of academic problems to prevent themselves on time, the risk situations.
\end{abstract}

Keywords: Violence. Sspace-school. Social representations

\footnotetext{
${ }^{1}$ Mestre em Ciências da Educação pela Universidade Lusófona de Humanidades e Tecnologias - Portugal.

${ }^{2}$ Psicóloga. Doutora em Psicologia Social pela Universidade Federal da Paraíba - UFPB. Professora da Universidade Federal do Cariri UFCA e da Universidade Regional do Cariri - URCA.

${ }^{3}$ Programa de Pós Graduação em Ciências da Educação da Universidade Lusófona de Humanidades e Tecnologias - Portugal
} 


\section{Introdução}

A violência no espaço escolar vem sendo objetivo de incansáveis pesquisas e trabalhos científico. Trata-se de um problema de caráter paradoxal e interpretação ambivalente. A "violência na Escola" reflete uma realidade do ambiente escolar, e do mundo onde está inserida, a escola, a clientela, e a comunidade. Encaminha para um repensar de novas formas de administração, melhoria na estrutura física, do aparato didático e democratização do ambiente escolar. Trata, portanto de uma questão complexa a ser pesquisada em toda sua origem e dimensão.

A percepção da violência no espaço escolar tende a mudar de acordo o olhar pelo qual esse termo é abordado. Isso nos leva às seguintes indagações: Diante do exposto, nos indagamos: Quais as características da violência nas escolas públicas? Quais os tipos mais comuns de violência observados nas escolas? Quais as Representações Sociais de violência que têm os professores?; Quais as estratégias que os mesmos utilizam para lidarem com a violência no espaço escolar?

\section{Violência Escolar: uma compreensão conceitual}

A temática da violência Escolar tem sido foco de constante e evoluídas pesquisas, debates, estudos minuciosos e aglomerações de informações de diferentes veiculações. Vários danos são os causados à Escola, as famílias e a sociedade ou grupos sociais e ao próprio agente que, antes de qualquer envolvimento é um ser humano, como tantos outros.

No entanto, vive assustado, esmagado, anulado, espremido e num caminho muitas vezes sem volta, cujo futuro é formado de fatigantes pressões, obscuridade e profundas seqüelas. Mas cadê aquele ser que por natureza nasce para ser livre, ter desejos, projetos e um mundo ao seu redor. Esse ser esbarra na organização: segundo Maffesoli (1987), de um lado, temos a organização, do outro, os indivíduos.

Os atos violentos, na maioria das vezes buscam em primeiro lugar responsabilizar alguém, encontrar um ou mais sujeitos e de cara justificar as vitimas ou a vitima e suas famílias mediante o acusado e nisso caracteriza outra realidade, a que promove os culpados com punições que justifiquem o tamanho do ato. Assim os gestores das instituições escolares e suas equipes bem como as autoridades assumem papel confortável mediante a sociedade sob dois ângulos: $\mathrm{O}$ de que encarou a situação de frente, puniu os acusados e fez justiça e do outro lado o de levar conforto a vitima para que não se sinta desprotegida, é a feliz frase: "a justiça foi feita". E ainda existe outro ponto, o de que tenha cumprido com o dever de escola e de autoridade e que tenha efeito de lição para que outros não façam. Mas a violência não para porque diz e se pergunta o filosofo Frances Dadoun (1998): 
A 'violência' é onipresente, a violência nos atinge, 'nos desconcerta' e nos toca por seus 'estrondos', 'nos ensurdece por gritos ininteligíveis' e 'por suas pressões cotidianas' [...] que nos 'amassam e nos estressam', não seria conveniente admitir que por isso esteja na própria raiz do humano?

O Filosofo continua se questionando e vai mais além ao buscar uma passagem bíblica para reafirmar sua tese de que "a violência é inerente do próprio homem". A Escola, sendo por excelência o local dedicado a educação e a socialização da criança e do adolescente vem se transformando em palco de agressão, desrespeito e autoritarismo. Segundo Miriam Abramovay (2009 - UNICEF), “o fenômeno da violência no cenário é mais antigo do que se pensa, prova disso é o fato de ele ser tema de estudo nos Estados Unidos desde a década de 1950". Com o passar dos anos esse fenômeno foi ganhando dimensão de caráter mais grave e mais corriqueiro, ou seja, fazendo parte do dia a dia das escolas e acontecendo cada vez mais em grau elevado e complexo. O que parecia brincadeiras de grupo passa a ser violência nas mais diversas classificações.

As Escolas procuram do jeito próprio de cada uma estabelecer políticas de combate a violência, mas esquecem de que é preciso começar pela prevenção pra depois passar pelo combate, controle e erradicação. No entanto tudo isso só pode ser pensado se visto a partir de contextos, se não fica apenas na procura de responsabilidade e pronto.

Mas o que é violência escolar? Para Abramovay (2009, P.30):

O que caracteriza como violência escolar varia em função do estabelecimento, de quem fala (professores, diretores, alunos e etc.), da idade e provavelmente do sexo. Não existe consenso em torno do seu significado [...] os termos para indicar violência também variam de um lugar para outro. Nos estados Unidos, diversas pesquisam usam a 'delinqüência juvenil'. Na Inglaterra, alguns autores defendem que o termo violência na escola só seja empregado no caso de conflitos entre estudantes e professores ou em relação a atividades que causem suspensão, atos indisciplinares e prisão.

Em toda a literatura que ao longo dos tempos vamos encontrando sobre essa temática, apesar das diferenças conceituais entre países, há de fato um consenso sobre ao fenômeno violência escolar: Não somente a violência física, todos os outros tipos de violência merecem e deve ter igual atenção, por muitos motivos, mas, sobretudo por se tratar de situações que podem ser graves e traumáticas.

Mesmo assim, nas falas dos profissionais da educação ainda é comum ouvirmos a seguinte descrição sobre violência: "são as agressões físicas e verbais praticadas entre alunos e de alunos contra professores e os danos causados ao patrimônio da escola." Isso é o de comum entre o pensamento dos docentes, gestores e coordenadores, enfim de todos que fazem parte do processo educacional pesquisado.

Mas o que pode significar esse discurso? Em conversas informais a escola deixa claro que cada dia vem buscando mais vinculo com a comunidade e com a família e ainda que todas as decisões, 
ações e acontecimentos são partilhados e votados com o conselho escolar. Mas as escolas não buscam contextualizar a problemática da violência e desvinculam da comunidade agindo como se fosse apenas mais um fato incorporado as atividades cotidianas do espaço urbano escolar. É nessa hora que a Escola deixa de ser o porto seguro para crianças, adolescente e jovens estudantes.

\section{O Problema}

A problemática da violência na escola aponta espaços teóricos e empíricos para explicar quais os motivos que levam a esse fenômeno, freqüentemente encontrado na dinâmica juvenil. Tal fato tem sido observado também em outros espaços sociais em que vivem os jovens, demonstrando o quanto eles têm investido em comportamentos violentos à procura de novas experiências. Na realidade, não há, necessariamente, problemas quanto a manifestação desses comportamentos. Isso faz parte da interação entre eles, diz respeito a uma condição do desenvolvimento social. A dificuldade surge quando tais experiências acontecem indiscriminadamente, implicando em condutas tangenciadoras das normas e desorganizadoras da ordem social. Não havendo um limite, tende-se ao risco pessoal e social.

Dessa forma, novas experiências indiscriminadas podem vir a gerar algumas atitudes e comportamentos, que passam a assumir etiquetas da delinquiência juvenil e, dessa forma, tornar-se, mais salientes, a saber: as formas de organização de grupos sociais que os jovens adotam - as gangs, a incitação a jogos de diversão violentos, as bagunças e vandalismo em festas, o alto e desenfreado consumo de álcool, tabaco e drogas (FORMIGA e GOUVEIA, 2003). Sob essa perspectiva, é possível, que à partir desses eventos, que ficam de fora do que se tem como norma social, compreendê-los através de duas dimensões: as condutas anti-sociais e as delitivas.

Quando considera-se que um jovem apresenta condutas do tipo anti-social ou delitiva, faz-se referência a um comportamento transgressor. Destaca-se aí, não somente os pobres, ou os negros, ou ainda os de classe econômica mais baixa, mas qualquer jovem. Segundo Formiga e Gouveia (2003), esses comportamentos não tem, atualmente, uma forma específica. São condutas de risco bastante evidentes. A conduta anti-social, por exemplo, associa-se a não conscientização das normas que deveriam ser respeitadas. Isso vai desde as normas de higiene dos ambientes que se frequenta, ao respeito para com os colegas. Assim, tal conduta caracteriza-se pelo incômodo causado, sem, contudo, implicar em danos físicos a outras pessoas. São mais travessuras de jovens ou, busca de romper com algumas leis sociais.

No caso da conduta delitiva, essa diz respeito às ações do indivíduo que possam ser concebidas como merecedoras de uma punição. Normalmente são aquelas capazes de causar danos 
mais graves, sejam eles morais ou físicos (Formiga e Gouveia, 2003). Assim, tais condutas devem ser consideradas como mais graves que as anteriores, representando uma real ameaça à ordem social vigente.

O que essas condutas têm em comum, parece ser a interferência no direito das pessoas, ameaçando o seu bem-estar. Neste sentido, diferenciam-se em função da gravidade das conseqüências por elas causadas. Possivelmente, os jovens praticam ou já praticaram algum tipo de conduta antisocial. Quando não inibidas, no momento adequado, através de uma prática parental responsiva ou exigente, pode implicar em grande possibilidade de que tal desafio se converta numa conduta delitiva (FORMIGA e GOUVEIA, 2003).

Explicações para muitas dessas condutas, têm eliciado variáveis que apontam, desde problemas de valores humanos, culturais, da estrutura e funcionalidade da família, de desenvolvimento moral, de hábitos de lazer e de estrutura e traços de personalidade, até a genética (COELHO JÚNIOR, 2001; FORMIGA, TEIXEIRA, CURADO, LÜDKE, e OLIVEIRA, 2003; FRIAS, SOTOMAYOR, VARELA, ZARAGOZA, BANDA, e GARCÍA, 2000; SOBRAL, 1996). Apesar de demonstrarem um poder explicativo e algum mérito quanto à direção para algumas soluções, principalmente no que se refere aos fatores preditivos do fenômeno da violência, ainda tem se mostrado promissor o poder explicativo da teoria personalística (BENET-MARTÍNEZ e JOHN, 1998; GAZZANIGA e HEATHERTON, 2005).

O estudo da personalidade aponta também uma perspectiva um tanto socializante, quanto à formação dos jovens e à estrutura da personalidade, na sua relação com as condutas humanas.

$\mathrm{Na}$ Psicologia, mesmo essa linha de pesquisa não sendo nova, frequentemente tem sido retomada, acrescentando informações para a compreensão do comportamento humano, mais especificamente para os comportamentos que conduzem à violência (também os anti-sociais e delitivos, os comportamento agressivo, uso de drogas, etc.).

Em resumo, o processo de escolarização ainda desempenha papel fundamental no desenvolvimento do indivíduo. Segundo Sawaya (2002), a escola detém funções variadas, como por exemplo: função social, quando compartilha com a família a educação de crianças e jovens, uma função política - quando contribui para a formação do cidadão e, uma pedagógica - na medida em que se faz um local privilegiado para construção de reflexões e conhecimento.

Mas a escola tem um impacto, que precisa ser analisado num contexto sociocultural mais amplo, pois os sujeitos ali se inserem, sobretudo com as suas diferentes práticas culturais e vivências familiares. E, nessa rede de histórias, edificam os vínculos que pulsam no ambiente escolar, podendo é claro, resultar em novas construções afetivas e também gerar adversidades intra e interpessoais. O tema violência apresenta-se pois, como um importante fenômeno a ser compreendido e contextualizado. 
A escola ainda parece um ambiente pouco explorado, enquanto um local perpetuador da violência. Mas, a violência na escola, caracteriza-se como um problema grave e complexo, um tipo muito visível de violência juvenil (LOPES NETO, 2005).

O objetivo do presente estudo é analisar as aspectos relacionados a violência nas escolas Públicas Municipais de Simões, Piauí. Para isso será necessário também: a) identificar os tipos mais comuns de violência observados nas escolas públicas municipais de Simões - PI; c) conhecer as Representações Sociais dos professores sobre violência e; c) distinguir as estratégias adotadas pelos professores nas escolas públicas de Simões, para lidarem com a violência no espaço escolar.

\section{Metodologia do Estudo}

Trata-se de um estudo quali-quantitativa, realizado no mês de agosto de 2014, com os educadores que atuam no Ensino Fundamental II. Os dados foram advindos de fonte direta do ambiente natural em duas escolas municipais do Ensino fundamental II, no município de Simões Piauí, Brasil. São elas: o Centro de Educação Municipal - CEM, localizada no perímetro Urbano, bairro do Centro, com 542 alunos e 30 professores, de acordo com o censo escolar de 2015 e, a Escola Eustáquio Carvalho, localizada no perímetro Rural, distante $18 \mathrm{~km}$ da sede, com 344 alunos matriculados em 2015 e 25 professores, de acordo com o censo escolar de 2015. Os dados foram coletados através de questionário, elaborado para o propósito deste estudo.

\section{Perfil dos professores}

Fizeram parte deste estudo 49 docentes, sendo 38 (77,6\%), do sexo feminino e 11 do sexo masculino $(22,4 \%)$. Maioria casado $(59,2 \%)$ ou solteiro $(18,3 \%)$. Suas idades, por classe, tiveram a seguinte distribuição: 3 professores com idades entre 20 e 29 anos (6,1\%); 17 professores com idades entre 30 a 39 anos (34,7\%); 18 professores com idades entre 40 a 49 anos (36,8\%) e, 11 professores com idades acima de 49 anos $(22,4 \%)$.

Com relação à escolaridade, a amostra se comportou da seguinte maneira: 4 dos professores possuía o Ensino Superior incompleto (8,2\%); 39 concluíram a Especialização (79,6\%); 03 já possuía o mestrado $(6,1 \%)$ e 02 já havia concluído o curso de doutorado (4,1\%). Apenas 01 professor não respondeu a esta questão $(2,0 \%)$.

Quanto ao tempo de docência, nota-se pois, um bom percentual de professores bem experientes. Observe-se que apenas 21,3\% tem até 10 anos de experiência docente. 23 professores possui entre 11 e 20 anos de docência (48,9\%); 10 professores possuem entre 21 e 30 anos de docência 
e, 4 professores afirmou ter entre 31 e 40 anos de docência. Dois professores não responderam a esta questão.

Acreditamos ser importante para uma educação de valores, reflexões mais maduras em relação às questões sobre a violência. A experiência docente profissional, certamente tende a conseguir melhores resultados. Sobre essa questão, Arroyo (2000), nos informa que não são somente os conhecimentos que são ensinados na escola. Mas também, as habilidades, as atitudes e os valores humanos. Estes quando se colocam em prática, tendem a produzir uma mudança mais efetiva no comportamento humano. Assim, a maturidade dos educadores em lidar com as temáticas voltadas uma contenção da violência no espaço escolar, deve ser vista como uma boa estratégia de mobilização, que nos inspire a reflexões políticas sobre a importante e urgente necessidade de capacitação profissional, nesta dimensão.

Indagados que foram sobre sua Renda familiar, 33 (67,3\%) responderam ganhar aproximadamente entre um e três salários mínimos vigente; $10(20,4 \%)$ ganham entre quatro a seis salários mínimos vigentes; 2 (4,1\% ) ganham entre sete e nove salários mínimos vigentes; 2 (4,1\%) ganham entre 10 ou mais salários mínimos vigentes. Outros $2(4,1 \%)$ não responderam a esta questão.

\section{Resultados e Discussões}

Quanto a identificar os tipos mais comuns de violência no espaço escolar, os sujeitos responderam inicialmente se já observaram ou não, episódios de Violência na escola. Observou-se que 98,0\% dos professores responderam que já observaram episódios de violência na escola. Indagados sobre quem estava envolvido, em 40 dos casos $(81,6 \%)$ foram episódios de violência entre os próprios alunos; Em cinco casos (10,2\%), a violência aconteceu entre aluno e professor; Um caso foi entre aluno e funcionário; em outro caso, professor e professor e, em um outro caso, a violência foi percebida entre professor e funcionário $(2,0 \%)$. Em um caso, o sujeito não respondeu $(2,0 \%)$.

Com relação ao Tipo de Violência observada descrita pelos sujeitos da amostra, das 157 respostas fornecidas pelos sujeitos, 44 (28,5\%) afirmaram já terem observado Violência Patrimonial. $43(27,2 \%)$ Violência física; 36 (22,8\%) Negligência; 33 (21,0) Violência psicológica e, 1 (0,5\%) observou Violência sexual.

Dentre as modalidades mais citadas estiveram presentes nas respostas, a Intimidação $(40,8 \%)$; a Difamação (16,3\%); o Assédio moral (12,2\%); a Injúria (4,1\%) e, outras $(26,5 \%)$.

Com relação ao local onde foram observadas as violências, Foram citados: Dentro da Escola $40(81,6 \%)$; Na rua $3(6,1 \%)$; Outro lugar $2(4,1 \%)$; Não responderam a esta questão $4(8,2 \%)$.

Indagados que foram sobre se os próprios sujeitos já haviam sofrido algum tipo de violência no espaço escolar, as respostas estão dispostas no gráfico a seguir. 


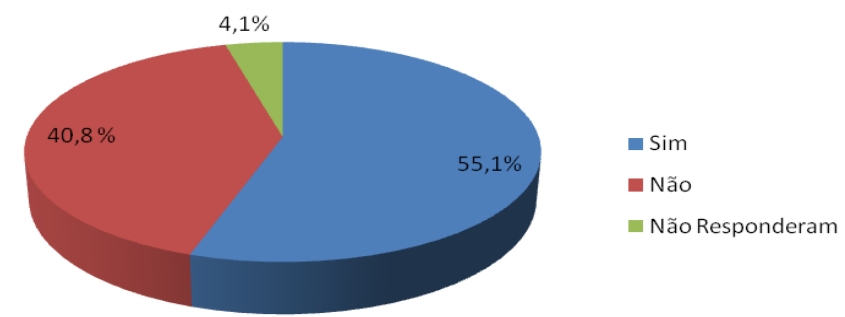

Gráfico 2 - Distribuição dos Sujeitos sobre já haver sofrido algum tipo de Violência no espaço escolar

Com relação ao tipo, 7 (14,3\%) afirmaram terem sofrido violência física; 13 (26,5\%) violência psicológica; 5 (10,2\%) negligência; 1 (2,0\%) violência patrimonial; 2 (4,1) Outro tipo de violência e, $21(42,9)$ não responderam a esta questão.

Embora o tipo de violência experienciada seja um importante indicador sobre a violência na escola, interessante também é a observação de Nunes e Abramovay (2003) que enumeraram alguns aspectos explicativos da violência escolar, a saber: 1. gênero - meninos se envolvem muito mais em situações de violência, isso seja como vítimas ou autores; 2. idade - em geral, o comportamento agressivo é associado ao ciclo etário; 3. etnia - há uma resistência dos alunos de minorias étnicas ao tratamento discriminatório, seja por parte de colegas ou por parte dos professores; 4. família normalmente alvo de controvérsia, em especial pelas "características sociais das famílias que são violentas"; 5. ambiente externo - as comunidades com sinais e sintomas de abandono ou de decadência parecem mais vulneráveis à violência; 6. Insatisfação ou frustração com as instituições e com a gestão pública - falta de equipamentos; de recursos didáticos; de recursos humanos; baixa qualidade no ensino; 7. exclusão social - as restrições à incorporação de parcela da população à política e recursos de apoio social; 8. exercício do poder - desestímulo e discriminações que contribuem para o desrespeito aos direitos humanos das pessoas.

Embora esteja presente no debate público, Sposito (2002) nos orienta que a pesquisa sobre violência associada a escola ainda é incipiente no Brasil. Dados do único levantamento nacional sobre a violência escolar, que foi publicado em 1998, mostrou três tipos de situações mais freqüentes: as depredações, os furtos ou roubos que atingem o patrimônio; as agressões físicas entre os aluno e as agressões de alunos contra professores.

Encontram-se praticamente ausentes, os estudos que tratam questões individuais associadas à violência escolar. As relações estabelecidas na própria escola, incluindo a vivência da violência, que teria um papel também relevante, porém ainda é pouco conhecida na visão do aluno. 
Id on Line Revista Multidisciplinar e de Psicologia

id on Line Multidisciplinary and Psychology Journal

\section{Representações sociais de Violência}

Quanto as Representações Sociais de violência relacionado aos sujeitos da amostra, os resultados foram dispostos conforme tabela a seguir.

Tabela 10: Distribuição da Categoria e Subcategorias das Representações Sociais de Violência pelos docentes da amostra. Simões - PI, 2014

\begin{tabular}{|c|c|c|}
\hline \multicolumn{3}{|c|}{ CATEGORIA: AÇÃO MALÉFICA INTENCIONAL - Ato de ferir ou maltratar } \\
\hline \multicolumn{3}{|c|}{ Subcategorias } \\
\hline Física & Psicológica & Social \\
\hline Agressão/brutalidade (25) & Desrespeito (16) & Injustiça (10) \\
\hline Destruição (4) & Humilhação (4) & Preconceito (7) \\
\hline Acusação verbal (2) & Medo/Pavor (4) & Difamação (5) \\
\hline Ferir (2) & Intimidação (3) & Negligência (3) \\
\hline Briga (1) & Insegurança (2) & Falta de Deus (3) \\
\hline Quebra do patrimônio (1) & Impingir medo (2) & Racismo (3) \\
\hline Tapas (1) & Maltratar (2) & Má educação (2) \\
\hline Palavrões (1) & Desvalorizacão (1) & Calúnia (2) \\
\hline Empurrão (1) & Conflito (1) & Injúria (2) \\
\hline Risco a vida (1) & Desconforto com algo (1) & Bulling/exclusão (2) \\
\hline Impingir dor com força (1) & Ofensa (1) & Impunidade (1) \\
\hline & Desavença (1) & Falta de religião (1) \\
\hline & Abuso (1) & Desestrutura familiar (1) \\
\hline & Violação (1) & Falta de limites (1) \\
\hline & Agitação (1) & Falta de ocupação (1) \\
\hline & Provocar raiva (1) & Tudo que fere a moral (1) \\
\hline $\mathbf{N}^{0}$ de Evocações $=40$ & $\mathbf{N}^{\mathbf{0}}$ de Evocações $=42$ & $\mathbf{N}^{\circ}$ de Evocações $=45$ \\
\hline
\end{tabular}

Fonte: Dados da Pesquisa (2014)

Com relação à questão as Representações Sociais de Violência, representadas pelas seguintes perguntas do questionário: Quando eu falo a palavra Violência, quais as primeiras palavras que lhe vêm a cabeça? e; O que significa Violência para você?? As respostas eliciadas foram distribuídas numa única Categoria: AÇÃO MALÉFICA INTENCIONAL.

A inspiração para a categoria adveio da própria etimologia da palavra violência. Advinda do latim violentia, a violência seria a qualidade do que é violento ou uma ação de maltratar outrem, a prática de uma ação maléfica intencional. A violência é portanto um comportamento deliberado, que pode vir a causar danos físicos, morais ou psíquicos ao próximo. Daí as subcategorias (Física, Psicológica e Social).

É importante se ter em conta que, para além da própria agressão física, a violência emocional através das ofensas ou de ameaças também pode vir a causar sequelas psicológicas e também sociais (impedimentos de ir e vir, não ser bem visto socialmente). 
Através da violência, é possível a alguém procurar-se impor ou obter algo pela força. Existem inúmeras formas de violência que são punidas por lei, tal como o assédio (moral, sexual). Em todo o caso, é importante ter-se em conta que os conceitos de violência variam conforme a cultura, contexto e época.

Neste sentido, esta categoria compreende a Violência como um ato de ferir ou de maltratar.

O estudo apresentou três subcategorias:

Subcategoria 1 - Física - Esta subcategoria compreende a violência física com o uso da força com o objetivo de ferir, machucar.

Apresentou 40 eliciações associadas, representando 31,5\% das falas.

Estudando a temática, Camacho (2000) nos aponta duas formas de violência vivenciadas na escola: física (agressões físicas, brigas e depredações) e não física (ofensas verbais, segregações, discriminações, desvalorizações e humilhações com palavras e atitudes de desmerecimento), neste último caso, muitas vezes, disfarçado, quase imperceptível. Essas experiências aterradoras ocorrem tanto com alunos como com professores e funcionários, nos mais diversos arranjos, quer os mesmos como protagonistas quer como vítimas.

A existência de bullying no ambiente escolar tem sido tema bastante investigado nos últimos anos. O termo em inglês é uma denominação específica para a violência nesse âmbito, evidenciando uma certa negatividade da violência nas relações entre pares, dando destaque ao ambiente escolar. O Bullying caracteriza-se por ações repetitivas de opressão, agressão e dominação de indivíduos ou grupos, sobre qualquer pessoa ou grupo, que possam sentir-se, nestes casos subjugados pela atitude dos primeiros. Trata-se de pessoas normalmente agressivas, valentes, usam jargões pejorativos com colegas, os aterrorizam e fazem sofrer. Normalmente ignoram, normas da escola, ameaçam, furtam, agridem, ofendem, intimidam ou depredam pertences dos colegas, dentre outras ações destrutivas (LOPES, ARAMIS, SAAVEDRA, 2003).

As vítimas de comportamentos agressivos, geralmente são pessoas com dificuldades para reagir. São retraídas, tornando forte o agressor e dificultando a visibilidade deste tipo de ação.

Outras formas de violência mais sutis, também fazem parte do dia-a-dia das instituições de ensino. Podendo-se considerar ainda, a própria instituição de ensino e, os próprios educadores como possíveis agentes de violência. Neste caso, quando há ações como a imposição de conteúdos sem o interesse dos alunos, ou o mesmo quando desprovido de significado para a vida dos alunos. A pressão do poder em conferir notas, a ignorância com relação a problemática dos alunos, o tratamento pejorativo dispensado, incluindo agressões verbais ou exposição do aluno ao ridículo, quando em casos de incompreensão sobre algum conteúdo de ensino (GUIMARÃES, 1992).

Reconhece-se que, em parte, tais formas de violência podem ser acontecimentos corriqueiros na prática educacional. Mas requerem transformações profundas. Não se pode contribuir para a sua banalização ou mesmo continuar a sua legitimação como mecanismo para resolver conflitos. 
De maneira geral, a violência física, manifesta uma afirmação de poder sobre o outro. Sua ocorrência é conseqüência da prática cotidiana de discriminação, de preconceito, da crise de autoridade do adulto e/ou da fraca capacidade profissional de criar mecanismos justos e democráticos de direcionar a vida escolar.

Outra forma de violência, talvez menos utilizada hoje, é a restrição do aluno ao convívio em sala de aula. Neste caso, o aluno é convidado a retirar-se para outro ambiente como a biblioteca ou outro espaço, instalando-se certa apatia, ressentimento e quem sabe, alienação, podendo implicar até em atitudes destrutivas e agressões físicas, por parte daqueles alunos que sofreram a frustração (LEMBO, 1975).

Observe-se que, a violência escolar possui muitas dimensões, não sendo algo simples de se pensar. Que tem implicações também extramuro escolar.

Subcategoria 2 - Psicológica - Nesta subcategoria concebe-se a violência como qualquer tipo de agressão emocional. É caracterizada pela rejeição, depreciação, discriminação, humilhação, desrespeito e por punições exageradas que impingem dor emocional. Apresentou 42 eliciações associadas, representando $33,1 \%$ das falas.

A violência psicológica implica em prejuízo emocional. No caso da baixa autoestima, o juízo pessoal de valor, que é externado nas atitudes que o indivíduo possa ter consigo mesmo, fica prejudicado. A autoestima é uma experiência subjetiva, onde as pessoas têm acesso mediante comportamentos observáveis e relatos verbais (COOPERSMITH, 1967). A percepção que o indivíduo faz acerca de seu próprio valor e sua avaliação de si mesmo em termos de competência, constituem os pilares fundamentais da autoestima. Assim, caso a pessoa sofra atitudes violentas, é possível uma maior probabilidade de serem associadas a um sentimento negativo de si. Dessa forma, a autoestima sofrerá uma baixa, em associação ao contexto.

Subcategoria 3 - Social - Neste caso, a violência foi concebida como uma espécie de construção social, transcendendo as questões puramente físicas e/ou emocionais.

Apresentou 45 eliciações associadas, representando $35,4 \%$ das falas.

Observa-se uma maior concentração das falas associadas a violência social (35,4\% das falas), seguida da violência psicológica $(33,1 \%)$ e da violência física (31,5\% das falas).

Ao que nos parece, o espaço escolar democrático, no qual as novas gerações são inseridas, tem se envolvido numa espécie de crise de autoridade docente. Este fato, a nosso ver, poderia ser testemunhado pelo aumento da violência no cenário escolar, no mundo inteiro, como se tem observado na mídia.

A autoridade delegada aos docentes, determinada pela instituição, é um dos dispositivos importantes de efetiva estruturação institucional. Nesse sentido, se a escola contemporânea apresentase cada vez mais como um espaço de embates que em muito ultrapassam os confrontos intelectual e/ou cultural, é natural supor, que padeça de uma certa ambigüidade, ou ineficácia, por seus dirigentes. 
Neste caso, é possível intuir tratar-se de uma crise, no mínimo ética. Ao que associamos a própria semente da violência social.

A crise da autoridade na educação, parece guardar uma estreita conexão com o que Arendt (1992) reconhece como crise da tradição, ou seja, uma crise de nossa atitude perante as nossas atitudes do passado. É, de certa forma, difícil para o educador lidar com essa ,maneira moderna, pois faz parte do seu ofício ser um mediador entre o velho e o novo, isso é, sua própria profissão exige um certo respeito extraordinário pelo passado. (ARENDT 1992)

Neste sentido, é importante salientar que, tradição não é sinônimo de anacronismo, bem como autoridade não seria sinônimo de despotismo. Pelo contrário. O patrimônio cultural precisa ser preservado, para que possa transformar as novas gerações. Assim, a questão da autoridade, para além da qualificação acadêmica do professor, passa a se pautar numa ética docente, reguladora e primordial do trabalho pedagógico. Mostrando-se como um importante antídoto contra a violência escolar.

Nesta direção, Arendt nos orienta que, embora a qualificação docente seja desejável e indispensável para a autoridade, por si só, não é o bastante. A qualificação, por maior que esta seja, nunca capacitará sozinha para a autoridade. A qualificação do professor apenas consistirá em conhecer o mundo, bem como ser capaz de instruir os outros sobre este. Sua autoridade porém, se assentará na responsabilidade que possa vir a assumir socialmente. Tal como um representante de todos os adultos, apontando à criança o que precisa ser visto. Sua responsabilidade, direitos e deveres perante o mundo.

\section{Estratégias para lidar com a violência}

Quanto as Estratégias utilizadas pelos professores para lidar com a violência no espaço escolar, os resultados foram dispostos conforme tabela a seguir.

Tabela 11: Distribuição das estratégias adotadas pelos professores para lidarem com a violência no espaço escolar. Simões - PI, 2014

\begin{tabular}{|c|c|c|}
\hline Estratégias & Freqüîncia & Percentual (\%) \\
\hline Palestras relacionadas com o tema & 28 & 27,0 \\
\hline Reuniões com a família & 19 & 17,6 \\
\hline $\begin{array}{l}\text { Maior divulgação da legislação da escola (Estatuto } \\
\text { e Regimento interno) e rigor no seu cumprimento } \\
\text { compreendendo: Advertência, Expulsão e/ou } \\
\text { Transferência }\end{array}$ & 17 & 16,7 \\
\hline Conversar com os alunos envolvidos & 10 & 9,3 \\
\hline Reuniões com Conselho Tutelar & 8 & 7,4 \\
\hline $\begin{array}{l}\text { Reuniões com Professores, Conselho Escolar e } \\
\text { Secretaria de Educação }\end{array}$ & 6 & 5,6 \\
\hline \multicolumn{3}{|l|}{ Continua... } \\
\hline $\begin{array}{l}18 \text { Ano 10, No. 29. Fevereiro/2016 - ISSN 1981-1179 } \\
\text { Ediçăo eletrônica em http://idonline.emnuvens.com.brid }\end{array}$ & & \\
\hline
\end{tabular}


Id on Line Revista Multidisciplinar e de Psicologia

id on Line Multidisciplinary and Psychology Journal

\begin{tabular}{lcc}
\hline Projetos & 5 & 4,6 \\
\hline Atividade recreativa para melhorar a socialização & 5 & 4,6 \\
\hline Eventos coletivos relacionados ao tema & 2 & 1,8 \\
\hline $\begin{array}{l}\text { Manter os alunos mais tempo em atividades de sala } \\
\text { de aula }\end{array}$ & 2 & 1,8 \\
\hline Nenhuma & 2 & 1,8 \\
\hline Afixação de Cartazes & 1 & 0,9 \\
\hline Dramatizações & 1 & 0,9 \\
\hline Total & $\mathbf{1 0 7}$ & $\mathbf{1 0 0 , 0}$ \\
\hline
\end{tabular}

Simões - PI, 2014.

Quanto às estratégias utilizadas pelos professores da amostra, para trabalharem com as questões relacionadas com a violência no espaço escolar, observou-se que a mais utilizada foram as palestrar $(27,0 \%)$, seguida de reuniões com a família $(17,6 \%)$ e Maior divulgação da legislação da escola (Estatuto e Regimento interno) e rigor no seu cumprimento compreendendo: Advertência, Expulsão e/ou Transferência (16,7\%).

Outras estratégias envolveram respectivamente: Conversar com os alunos envolvidos $(9,3 \%)$; Reuniões com Conselho Tutelar (7,4\%); Reuniões com Professores, Conselho Escolar e Secretaria de Educação (5,6\%); Projetos (4,6\%) e, Atividade recreativa para melhorar a socialização $(4,6 \%)$

Foram citadas com menor ênfase, as seguintes estratégias: Eventos coletivos relacionados ao tema $(1,8 \%)$; Manter os alunos mais tempo em atividades de sala de aula $(1,8 \%)$; Nenhuma $(1,8 \%)$; Afixação de Cartazes $(0,9 \%)$ e Dramatizações $(0,9 \%)$.

Neste sentido, a contribuição psicanalítica seria por meio da palavra e do incentivo a projetos que busquem a escuta dos sujeitos envolvidos em situações de conflito, possibilitando um trabalho coletivo na instituição escolar. Essa perspectiva traria uma inspiração ética mais profunda, na medida em que a retomada da palavra permitiria uma abertura de alternativas aos atos de violência. "Eis a forma analítica de dispensar o aprisionamento ao discurso do mestre contemporâneo para dar lugar ao saber fazer de cada um", apresenta Barros-Brisset: "convidando cada um a tomar a palavra para falar mais sobre isso" (BARROS-BRISSET, 2013, p.6).

Como bem sugere Lacadée (2000), em vez de medidas apenas proibitivas, é preciso autorizar as pessoas a respeitarem-se a si mesmos, para que dessa forma, eles possam se reconhecer como sujeitos na sociedade. A escola se ocupa da formação, daqueles que precisam ser amparados em algum momento de suas vidas. Educar é uma forma de ajudar a construir um sentido para a vida. É refletir, é despertar, nos jovens, o desejo e a alegria de viver. Para além do repasse de conhecimentos universais, a escola precisa acolher o novo que cada jovem traz em seu corpo e em seu discurso. 


\section{Considerações Finais}

As explicações para a violência na instituição educativa não são simples, em geral, relacionam-se à forma de como acontece a organização da escola, como os métodos didáticos são empregados, como os procedimentos institucionais são aplicados e, principalmente, qual o significado que a escola assume para os alunos. Elas tendem a se relacionarem também ao processo de atribuição de identidades, da mesma maneira como se relacionam à violência social. Que, como nos orienta Dubet (2003), entra na escola pela pobreza, pela dificuldade, pela marginação, através da delinquência e também pelo prolongamento da idade de escolarização obrigatória. Tal situação, às vezes, é agravada pelo desemprego, pelo tráfico de drogas e /ou crime organizado, pela baixa renda e, em muitos casos pela situação de miséria e pela desigualdade social presente na sociedade brasileira (TAVARES DOS SANTOS, 2001; ZALUAR, 2004).

Nas escolas, parece haver um discurso sobre a importância do coletivo e sobre uma formação para a cidadania. Todavia, como efetivar ações deste tipo em uma sociedade na qual o impera o individualismo? Ou, como indaga Martuccelli e Barrere (2001), como querer uma moral e uma ética como norteadores, em uma sociedade quando os significados ainda precisam ser construídos por cada um? A violência de jovens no âmbito escolar e também fora dele, parece mais estar relacionada à exclusão social e cultural. É tanto material como simbólica. Diz respeito a falta de trabalho e à uma necessidade de consumo constantes, que a maioria de nós não dá conta.

Em resumo, cabe à escola reconhecer esse desencontro entre ela e as populações excluídas e, procurar construir uma escola um pouco menos estigmatizante em relação aos alunos, de maneira a preservar sua dignidade. Ainda que os alunos de escolas públicas, em geral, quase sempre só sejam encaminhados a profissões menos qualificadas, essa trajetória não precisa ser acompanhada por um processo de estigmatização e desvalorização deles enquanto pessoas. Agir para que se construa uma relação baseada no respeito, parece-nos ser, uma condição mais que fundamental para que se possa reduzir a violência no contexto escolar e também fora dela.

\section{Referências}

ABRAMOVAY, Mirian. Violência escolar: O bê a ba da intolerância e da discriminação - Brasil, Ed. UNICEF, 2009.

ARENDT, Hannah. Entre o passado e o futuro. $3^{\text {a }}$ ed. São Paulo: Perspectiva, 1992.

ARROYO, Miguel. Ofício de mestre: imagens e auto-imagens. 3. ed. Petrópolis: Vozes, 2000. 
BARROS-BRISSET, Fernanda. Por uma política de atenção integral ao louco infrator. Belo Horizonte: TJMG. Disponível em: . Acesso em: jan. 2013, 2010.

BENET-MARTÍNEZ, V. ; JOHN, O. P. Los cinco grandes across cultures and ethnic groups: Multitrait multimethod analyses of the Big Five in Spanish and English. Journal of Personality and Social Psychology, 75, 729-750, 1998.

CAMACHO, L. M.Y. Violência e indisciplina nas práticas escolares de adolescentes: um estudo das realidades de duas escolas semelhantes e diferentes entre si. São Paulo. Tese (dout.) Universidade de São Paulo, 2000.

COELHO JUNIOR, L. L. Uso potencial de drogas em estudantes do ensino médio: Suas correlações com as prioridades axiológicas. Dissertação (Mestrado em Psicologia Social). Universidade federal da Paraíba, João Pessoa, PB, 2001.

DADOUN, R. A. Violência. Ensaio a cerca do homo violens. Trad. P. Ferreira, C. Carvalho, Rio de Janeiro: Difel, 1998.

DUBET, F. A escola e a exclusão. Cadernos de Pesquisa, São Paulo, n.119, p.29-45, jul., 1998. Disponível em: www.scielo.com.br/scielo. Acesso em: 12/10/2015.

29-45, julho, 2003.

A escola e a exclusão. Tradução de Neide Rezende. Cadernos de Pesquisa, n. 119, p.

FORMIGA, N. S.; GOUVEIA, V. V. Adaptação e validação da escala de condutas anti-sociais e delitivas ao contexto brasileiro. Revista Psico, v. 34, n. 2, p.367-388, 2003.

FORMIGA, N. S.; TEIXEIRA, J.; CURADO, F.; LÜDKE, L. \& OLIVEIRA, A. R. N. A predição das condutas anti-sociais e delitivas a partir dos traços de personalidade. XXXIII Reunião anual da sociedade brasileira de psicologia. Psicologia: Compromisso com a vida, (p. 381). Belo Horizonte MG: Sociedade Brasileira de Psicologia. [Resumos], 2003.

FRÍAS, M. A., SOTOMAYOR, M. P., VARELA, C. B. C., ZARAGOZA, F. O., Banda, A. L. B., \& García, A. S. Predictores de la delincuencia juvenil. La Psicología Social en México, (8), 486-492, 2000.

GAZZANIGA, M. S.; HEATHERTON, T. F. Personalidade. In Ciência psicológica: mente, cérebro e comportamento (pp. 470-496). Porto Alegre: Artmed, 2005.

GUIMARÃES, A. M. A Escola e a ambigüidade. In: Silva, A. et al. O Papel do diretor e a escola de $1^{\circ}$ grau. São Paulo. p.51-74, 1992.

LACADÉE, P. Da norma da conversação ao detalhe da conversação. In P. Lacadeé, \& F. Monier (Orgs.), Le pari de la conversation. Paris: Institut du Champs Freudien: CIEN Centre interdisciplinaire su l’Enfant, 2000.

LEMBO, J. M. Porque falham os professores. São Paulo: EPU, 1975.

LOPES NETO, Aramis A. Bullying comportamento agressivo entre estudantes Bullying aggressive behavior among students. Jornal de Pediatria. Vol. 81, Nº5(Supl),S165, 2005. 
LOPES, N.; Aramis, A.; Saavedra, L.H. Diga não para o Bullying: programa de redução do comportamento agressivo entre estudantes. Rio de Janeiro, 2003.

MAFESSOLI, M. Dinâmica da violência. Trad. C. M. V. França. São Paulo: Editora Revista dos Tribunais, (biblioteca Vértice:v.7), 1987.

MARTUCCELLI, D.; BARRERE, A. A escola entre a agonia moral e a renovação ética. Educação e Sociedade, 2001.Campinas, ano XXII, v.22, n.76, p. 258-77, out. Disponível em: www.scielo.com.br/scielo. Acesso em: 12/10/2015.

NUNES, M. F. R; ABRAMOVAY, M. Escolas inovadoras: experiências bem- sucedidas em escolas públicas. Brasília: Unesco; Fundação W. K. Kellogg; Unirio, 2003.

POMBO, O. $O$ Insuportável brilho da Escola, 2003. Disponível em: $\mathrm{htt} / / \mathrm{www}$.educ.fc.ul.docentes/investigação/brilhoescola.pgf. acesso em: 08-06-2012.

SAWAYA, S. M. Novas perspectivas sobre o sucesso e o fracasso escolar (pp. 197-213). In Oliveira, M. K., Sousa, D. T. R., \& Rego, T. C. (Org.). Psicologia, educação e as temáticas da vida contemporânea. São Paulo: Editora Moderna, 2002.

SOBRAL, J. Psicología social jurídica. In J. L. Álvaro, A. Garrido, \& J. R. Torregrossa (Eds.), Psicología social aplicada (pp. 254-268). Madrid: McGraw-Hill, 1996.

SPOSITO, M. P. A. Instituição escolar e a Violência. Cadernos de Pesquisas. São Paulo, v. 104, p. 58-75, 2002.

ZALUAR, A. Integração perversa: pobreza e tráfico de drogas. Rio de Janeiro: FGV, 2004.

\section{Como citar este artigo (Formato ABNT):}

CARVALHO, Maria das Graças de; OLIVERA, Gislene F. de, CARITA, Ana. Representações da Violência por Professores. Id on Line Revista de Psicologia, Fevereiro de 2016, vol.10, n.29. p. 07- 22. ISSN 1981-1179.

Recebido: $10 / 02 / 2016$

Aceito: 26/02/2016 